\title{
RNF6 promotes the migration and invasion of breast cancer by promoting the ubiquitination and degradation of MST1
}

\author{
YAJUAN HUANG $^{1}$, YUFENG ZOU ${ }^{2,3}$ and ZHIGANG JIE ${ }^{1}$ \\ ${ }^{1}$ Department of General Surgery, The First Affiliated Hospital of Nanchang University, Nanchang, Jiangxi 330009; \\ ${ }^{2}$ Department of Breast Surgery; ${ }^{3}$ Jiangxi Provincial Key Laboratory for Breast Diseases, \\ The Third Hospital of Nanchang, Nanchang, Jiangxi 330006, P.R. China
}

Received November 6, 2019; Accepted August 26, 2020

DOI: $10.3892 /$ etm.2021.11041

\begin{abstract}
Ring finger protein 6 (RNF6), a member of E3 ubiquitin ligases, plays a potential role as a tumour promoter in numerous carcinomas. However, the role and expression of RNF6 in breast cancer (BC) remains to be elucidated. The present study showed that RNF6 upregulation was detected in BC tissues and was associated with short survival in patients with BC. Multivariate analysis also revealed that RNF6 overexpression is an independent predictor for poor outcome of patients with BC. Furthermore, migration and metastasis assay indicated that RNF6 silencing significantly inhibited the invasion and migration of BC cells in vivo and in vitro, and RNF6 suppression decreased YES-associated protein (YAP) expression. RNF6 promoted the metastatic ability of BC cells via YAP. Mechanistically, RNF6 interacts with mammalian STE20-like protein kinase 1 (MST1), a key factor that regulates YAP, and promoted its ubiquitination and degradation. Additionally, RNF6 regulated YAP signalling by promoting ubiquitination and degradation of MST1 in BC. Taken together, these data may highlight a role of RNF6 in BC, which could serve as a valuable prognostic indicator and potential therapeutic target for patients with BC.
\end{abstract}

\section{Introduction}

Breast cancer (BC) is one of the most common cancers worldwide and is the main cause of mortality of female patients with cancer $(1,2)$. Surgery and systemic chemotherapy can cure $70 \%$ of patients with $\mathrm{BC}$, but the 5-year survival rate of those with metastatic disease remains poor (3). Therefore, investigating the molecular mechanism of BC metastasis may be helpful for the formulation of treatment strategies for breast cancer.

Correspondence to: Professor Zhigang Jie, Department of General Surgery, The First Affiliated Hospital of Nanchang University, 17 Yongwai Street, Nanchang, Jiangxi 330009, P.R. China E-mail: zhigangjie1963@126.com

Key words: ring finger protein 6, breast cancer, mammalian STE20-like protein kinase, migration and invasion, ubiquitination, degradation
Ring finger protein 6 (RNF6), a member of E3 ubiquitin ligases, regulates a number of target genes that are important for cell growth and survival $(4,5)$. Recent accumulating evidence indicated that RNF6 could promote the degradation of its target protein by a ubiquitin proteasome (6). A number of studies confirmed that RNF6 is a carcinogenic gene in numerous types of cancer, including prostate cancer, oesophageal squamous cell carcinoma and lung adenocarcinoma (7-9). For instance, the expression levels of RNF6 are elevated in colorectal cancer, and high RNF6 levels is correlated with poor prognosis $(4,5)$. However, the effect of RNF6 on the invasion and metastasis of $\mathrm{BC}$ and its potential mechanisms remain to be elucidated.

The Hippo signalling pathway is an evolutionarily conservative signalling pathway that plays a key role in controlling the invasion and migration of tumor cells (10). At the core of the Hippo pathway is a kinase cascade that activates mammalian STE20-like protein kinase (MST) 1/2 phosphorylation and activates large tumour suppressor kinase $1 / 2$, which phosphorylates and inhibits the two major downstream effectors of the Hippo pathway, YES-associated protein (YAP) and transcriptional co-activator with PDZ-binding motif (TAZ) $(11,12)$. Dephosphorylated YAP and TAZ enter the nucleus and induce target gene expression, which promotes cell migration (13). Studies demonstrated that YAP is overexpressed in some tumours, and sustained expression of YAP promoted growth and tumour occurrence, suggesting that the Hippo pathway plays a key role in tumorigenesis $(14,15)$. However, the mechanism of YAP expression regulation in $\mathrm{BC}$ is still unclear.

To the best of our knowledge, the present study first found that RNF6 was significantly upregulated in breast cancer tissues compared with the adjacent normal tissues. The expression and function of RNF6 in breast cancer cells was then studied. RNF6 was also identified as a possible E3 ligase of MST1 (also known as S100A4), as it interacted with and promoted the degradation of MST1. These data might highlight the role of RNF6 in BC, which could serve as a valuable prognostic indicator and potential therapeutic target for patients with BC.

\section{Materials and methods}

Patients and samples. BC samples were obtained from 146 patients (age, 42-72 years) with breast cancer at the Third Hospital of Nanchang and the First Affiliated Hospital 
of Nanchang University (China) from December 2007 to December 2015, immediately snap-frozen in liquid nitrogen and stored at $-80^{\circ} \mathrm{C}$ for further analysis. All patients provided written informed consent. The research procedure was approved by the Ethics Committee of the Third Hospital of Nanchang and the First Affiliated Hospital of Nanchang University.

Cell lines. BC cell lines (BT549, MDA-MB-231, MDA-MB-453 and MCF7) and normal human mammary gland cells (MCF10A) were purchased from American Type Culture Collection. Cell lines were cultured in DMEM (Gibco; Thermo Fisher Scientific, Inc.) supplemented with FBS (Gibco; Thermo Fisher Scientific, Inc.) to a final concentration of $10 \%$ at $37^{\circ} \mathrm{C}$ in a humidified incubator containing $5 \% \mathrm{CO}_{2}$.

Western blot assay. Protein from BT549, MDA-MB-231, MDA-MB-453, MCF7 and normal human mammary gland cells (MCF10A) cells was extracted using RIPA lysis buffer (MilliporeSigma) according to the manufacturer's instructions. The total protein concentration was measured with a BCA protein assay kit (Takara Biotechnology Co., Ltd.). The samples $(20 \mu \mathrm{g})$ were separated via $10 \%$ SDS-PAGE, then transferred onto PVDF membranes. The membranes were blocked with 5\% non-fat milk for $2 \mathrm{~h}$ at room temperature, then treated with the following primary antibodies overnight at $4^{\circ} \mathrm{C}$. The following primary antibodies were used: Anti-RNF6 (1:1,000; cat. no. ab204506; Abcam), anti-YAP (1:500; cat. no. 13584-1-AP; ProteinTech Group, Inc.), anti-MST1 (1:1,000; cat. no. 3682; Cell Signaling Technology, Inc.), anti-ubiquitin (1:1,000; cat. no. 10201-2-AP; ProteinTech Group, Inc.), anti-Cyr61 (1:500; cat. no. 26689-1-AP; ProteinTech Group, Inc.), anti-connective tissue growth factor (1:500; cat. no. 23936-1-AP; ProteinTech Group, Inc.) and anti-cyclin E (1:500; cat. no. 11554-1-AP; ProteinTech Group, Inc.). Tubulin expression (1:2,000; cat. no.11224-1-AP; ProteinTech Group, Inc.) was used as a loading control. After washing three times with Tris-buffered saline- $0.1 \%$ Tween-20, the membranes were incubated with HRP-conjugated goat anti-rabbit $\operatorname{IgG}$ secondary anti-body (1:5,000; cat. no. ab6728; Abcam) for $2 \mathrm{~h}$ at $4^{\circ} \mathrm{C}$. Finally, the protein bands were visualized with ECL system (Thermo Fisher Scientific, Inc.) and analyzed by densitometry using software ImageJ (National Institutes of Health; version 1.48).

Immunohistochemistry (IHC) staining. All BC tissue specimens were fixed with $10 \%$ neutral formaldehyde solution for 4-6 $\mathrm{h}$ at room temperature, and were dehydrated, waxed and wrapped. Then, the tissues were cut into 4-6 $\mu \mathrm{m}$ sections. The tissue sections were baked at $60^{\circ} \mathrm{C}$ overnight. Sections were blocked using 2\% BSA (Sangon Biotech Co., Ltd.) for $1 \mathrm{~h}$ at room temperature. Anti-RNF6 (1:1,000; cat. no. ab204506; Abcam) was applied to paraffin-embedded sections following microwave antigen retrieval for $10 \mathrm{~min}$ in $0.01 \mathrm{~mol} / 1$ citrate buffer ( $\mathrm{pH}, 6.0)$. Specimens were treated with $0.3 \%$ hydrogen peroxide in methanol for $15 \mathrm{~min}$ at room temperature following incubation with primary antibody to block endogenous peroxidase activity and blocked with human serum (Gibco; Thermo Fisher Scientific, Inc.) to minimize background reactivity at room temperature. Following the primary antibody incubation, the sections were rinsed thrice with PBS for $5 \mathrm{~min}$ and incubated with $50 \mu 1 \mathrm{HRP}$-conjugated secondary goat anti-rabbit antibody (product code ab6721; 1:1,000; Epitomics; Abcam) at room temperature for $20 \mathrm{~min}$. Then, samples were washed and incubated with $\mathrm{ABC}$ amplification system for $30 \mathrm{~min}$ at room temperature (ready to use; cat. no. PK-7 200; Vector Laboratories, Inc.). Finally, the chromogenic substrate 3,3'-diaminobenzidine (DAB) was added. Furthermore, the nuclei were stained with hematoxylin (ScyTek Laboratories, Inc.) for $1 \mathrm{~min}$ at room temperature. Images were obtained using an image analyzer system (Olympus BH-2 microscope; Olympus Corporation), digitized and the DAB signal was quantified by ImageJ $1.51 \mathrm{w}$ software (National Institutes of Health).

Constructs and plasmids. RNA duplexes for short hairpin (sh)RNA-mediated RNF6 and YAP knockdown were synthesized by Shanghai GenePharma Co., Ltd. shRNF6, pcDNA3.1-RNF6, shMST1, pcDNA3.1-MST1 and pcDNA3.1-YAP plasmids were also purchased from Shanghai GenePharma Co., Ltd. shRNA plasmid and overexpression vector transfection in BC cells was performed using Lipofectamine $^{\mathrm{TM}} 3000$ (Invitrogen; Thermo Fisher Scientific, Inc.) according to the manufacturer's protocol. The concentration of shRNF6 and shYAP was $6 \times 10^{8} \mathrm{TU} / \mathrm{ml}$, and $1 \times 10^{6}$ cells were transfected with $R N F 6$ and YAP plasmids $(10 \mu \mathrm{g})$. The Lipofectamine $^{\mathrm{TM}}$ 3000-plasmids complex was formed by mixing for $20 \mathrm{~min}$ at room temperature. Then, complex was added to the cells and the cells were cultured in serum-free Opti-MEM (Gibco; Thermo Fisher Scientific, Inc.) at $37^{\circ} \mathrm{C}$ for $4 \mathrm{~h}$, followed by incubation in serum-containing medium (DMEM; Gibco; Thermo Fisher Scientific, Inc.) at $37^{\circ} \mathrm{C}$ for $72 \mathrm{~h}$. After $72 \mathrm{~h}$, the cells were collected and washed twice with PBS. Sequences were as follows: RNF6, shiRNA-1, 5'-UUUCUGAGUCUCCAUCACUUGCCGC-3', and shRNA-2, 5'-UUUCGCGAGUCUCUCUACUUCACGC-3'; YAP, shRNA-1, 5'-AAGGUGAUACUAUCAACCAAA-3', and shRNA-2, 5'-AAGACAUCUUCUGGUCAGAGA-3' and MST1, shRNA 1, 5'-GGGCACTGTCCGAGTAGCAGC-3', and shRNA 2, 5'-CCGTCTTTCCTTGAATACTTT-3'.

In vivo ubiquitination assay. For the in vivo ubiquitination assay, RNF6-deficient or RNF6-overexpressing BC cells were treated with MG132 $(15 \mu \mathrm{g} / \mathrm{ml}$; cat. no. A2585; APeXBIO Technology LLC) for $4-6 \mathrm{~h}$ at $37^{\circ} \mathrm{C}$. Following further incubation for 2-3 h, cell lysates were immunoprecipitated with anti-MST1 antibody (1:1,000; cat. no. 3682; Cell Signaling Technology, Inc.). Ubiquitination levels of MST1 were measured with an anti-ubiquitin (Ub) antibody (1:1,000; cat. no. 10201-2-AP; ProteinTech Group, Inc.).

RNA isolation and reverse transcription-quantitative PCR (RT-qPCR). Total RNA was isolated from BC and non-tumour adjacent issues using TRIzol ${ }^{\circledR}$ reagent (Invitrogen; Thermo Fisher Scientific, Inc.) according to the manufacturer's protocol. RNA was reverse transcribed into cDNA using a Prime Script RT Reagent kit with gDNA Eraser (Takara Biotechnology Co., Ltd.) according to the manufacturer's instructions. cDNA was used as a template to perform qPCR on the ABI PRISM 7500 auto fluorescence PCR instrument (Applied Biosystems; 
Thermo Fisher Scientific, Inc.) using the SYBR Premix Ex Taq Kit (Takara Biotechnology Co., Ltd.).

The primer sequences were as follows: RNF6 forward, 5'-AGAAGATGGCAGCAAGAGCG-3' and reverse, 5'-TCA AGTCAGGCTGAGATGCTAGT-3'; MST1 forward, 5'-GGG TCCCAGTAGCCAAGAT-3' and reverse, 5'-GAGGCACCA CATACCATTCA-3'; YAP forward, 5'-GGATTTCTGCCT TCCCTGAA-3' and reverse, 5'-GATAGCAGGGCGTGAGGA AC-3'; GAPDH forward, 5'-CTTCGCTCTCTGCTCCTC CT-3' and reverse, 5'-GTTAAAAGCAGCCCTGGTGA-3'.

Migration and invasion assay. Transwell-based migration and invasion assays in BC cell lines were conducted as previously described (6), with minor modifications. For the cell invasion assay, the polycarbonate membranes of the upper compartment of the chambers were precoated with a matrix gel.

In vivo metastasis assay. An experimental model of lung metastasis was used to investigate the effects of RNF6 on $\mathrm{BC}$ metastasis. A total of 60 female BALB/c nude mice (age, 4-6 weeks; weight, 18-20 g; Shanghai SLAC Laboratory Animal Co., Ltd.) were maintained in a $20^{\circ} \mathrm{C}$ environment with 40-60\% humidity and a 12/12-h light/dark cycle, andwith a standardized barrier system at the Experimental Animal Center of Nanchang University. For each nude mouse, 1x10 MDA-MB-231 cells in $100 \mu$ l PBS were injected via the tail vein. The mice were sacrificed 6 weeks after tumor implantation. The nude mice were euthanized by cervical dislocation; cessation of breathing, corneal reflex and heartbeat were considered to indicate mortality. The lungs and major organs were removed and fixed with $10 \%$ formalin. Subsequently, consecutive tissue sections $(4-6 \mu \mathrm{m})$ were made from each block of the lung. The sections were stained with hematoxylin-eosin staining (H\&E). These slides were examined systematically using an image analyzer system (Olympus BH-2 microscope; Olympus Corporation). The animal study was approved by the Ethics Committee for Animal Experiments of The First Affiliated Hospital of Nanchang University and The Third Hospital of Nanchang (approval no. NDYFY2013D078).

Immunofluorescence assay. A total of $2 \times 10^{3}$ MDA-MB-231 cells were placed on slides for $24 \mathrm{~h}$, fixed with $4 \%$ polyformaldehyde for $30 \mathrm{~min}$ at room temperature, then treated with $0.3 \%$ Triton $\mathrm{X}-100 / \mathrm{PBS}$ for $5 \mathrm{~min}$ at room temperature. The cells were then sealed with 5\% BSA (Beijing Solarbio Science \& Technology Co., Ltd.) at room temperature for $1 \mathrm{~h}$ and stained overnight with antibodies (Anti-RNF6 1:500; cat. no. ab204506; Abcam and anti-MST1 (1:500; cat. no. abab76822); Abcam.) at $4^{\circ} \mathrm{C}$. Following primary antibody incubation, cells were incubated with fluorescent dye-bound secondary antibodies (both 1:200; both Invitrogen; Thermo Fisher Scientific, Inc.; cat. nos. A32723 and A-11035) for $1 \mathrm{~h}$ at room temperature and stained with DAPI $(5 \mathrm{mg} / \mathrm{ml})$ for $15 \mathrm{sec}$ at room temperature.

Co-immunoprecipitation (Co-IP) and glutathione $S$-transferase (GST) pull-down experiments. For the co-IP assay, RNF6 knockdown or overexpressed BC cells were exposed to MG132 (15 $\mu \mathrm{g} / \mathrm{ml}$; cat. no. A2585; APeXBIO Technology LLC) for $4-6 \mathrm{~h}$ at $37^{\circ} \mathrm{C}$ before harvesting.
Subsequently, theBC cells were extracted using RIPA lysis buffer (MilliporeSigma) according to the manufacturer's instructions, then the cell lysate was immunoprecipitated with anti-MST1 and the ubiquitination levels of MST1 were measured with anti-Ub antibody. For the GST pull-down assay, BL-21 competent Escherichia coli (Beijing Solarbio Science \& Technology Co., Ltd.) was transformed with shRNF6 or PcDNA-3.1-RNF6 plasmids and cultured overnight at room temperature. GST fusion protein expression was induced with isopropyl $\beta$-D-thiogalactoside $(1 \mathrm{mg} / \mathrm{ml})$ for $3-5 \mathrm{~h}$ at $20-30^{\circ} \mathrm{C}$. Cells were harvested in RIPA lysis buffer(Beyotime Institute of Biotechnology) and homogenized by sonication. Following centrifugation $\left(14,000 \mathrm{~g}, 5 \mathrm{~min}, 4^{\circ} \mathrm{C}\right)$, GST fusion proteins in supernatant were purified by glutathione sepharose 4B beads according to the manufacturer's instructions (GE Healthcare). An aliquot $(5 \mu \mathrm{g})$ of glutathione or GST-RNF6 protein was added to cell lysates, followed by overnight incubation with gentle rotation at $4^{\circ} \mathrm{C}$ and addition of glutathione-sep harose $4 \mathrm{~B}$ beads (GE Healthcare) for $3 \mathrm{~h}$ at room temperature. The beads were collected by centrifugation $\left(14,000 \mathrm{~g}, 5 \mathrm{~min}, 4^{\circ} \mathrm{C}\right)$ and washed with ice-cold lysis buffer. MST1 protein was detected by western blotting.

Cycloheximide $(\mathrm{CHX})$ chase assay. To inhibit MST1 protein synthesis in BC cells, cells were treated with $100 \mu \mathrm{g} / \mathrm{ml} \mathrm{CHX}$ (Sigma-Aldrich; Merck KGaA) at $37^{\circ} \mathrm{C}$ for $4 \mathrm{~h}$. A total of $5 \times 10^{5}$ MDA-MB-231 cells were transfected with shRNA or shRNF6 plasmids( 6x10 ${ }^{8} \mathrm{TU} / \mathrm{ml}$, Shanghai GenePharma Co., Ltd.) using Lipofectamine 3000 (Invitrogen; Thermo Fisher Scientific, Inc.) The Lipofectamine ${ }^{\mathrm{TM}}$ 3000-plasmids complex was formed by mixing for $20 \mathrm{~min}$ at room temperature. Then, complex was added to the cells and the cells were cultured in serum-free Opti-MEM (Gibco; Thermo Fisher Scientific, Inc.) at $37^{\circ} \mathrm{C}$ for $4 \mathrm{~h}$, followed by incubation in serum-containing medium (DMEM; Gibco; Thermo Fisher Scientific, Inc.) at $37^{\circ} \mathrm{C}$ for $48 \mathrm{~h}$. At $48 \mathrm{~h}$ post-transfection, the cells were harvested at different time points $(0,1,3$ and $5 \mathrm{~h})$ following CHX treatment and the expression of MST1 protein was detected by western blotting.

Statistical analysis. Data are presented as the mean \pm SD of three independent experiments. The unpaired Student's t-test method was used to evaluate the significance between two groups while the one-way analysis of variance method followed by Tukey's test was used to estimate the difference among multiple groups. The association between RNF6 expression and clinicopathological characteristics of patients with BC was analysed using Fisher's exact probabilities test. One-way ANOVA followed by Tukey's post hoc test was used for multiple comparisons. All statistical calculations were performed using SPSS 19.0 (IBM Corp.) and all graphs were constructed with GraphPad Prism 6.0 (GraphPad Software, Inc.). $\mathrm{P}<0.05$ was considered to indicate a statistically significant difference.

\section{Results}

RNF6 overexpression is correlated with poor outcome in patients with BC. The potential role of RNF6 in the development and progression of BC was investigated. Initially, 
A

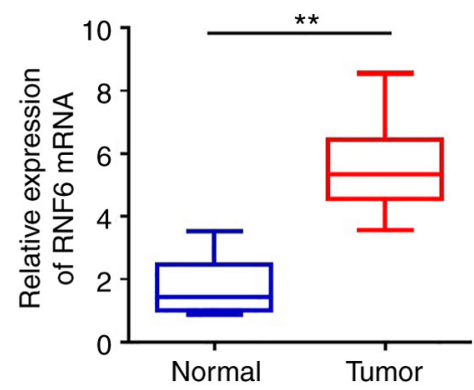

$\mathrm{C}$

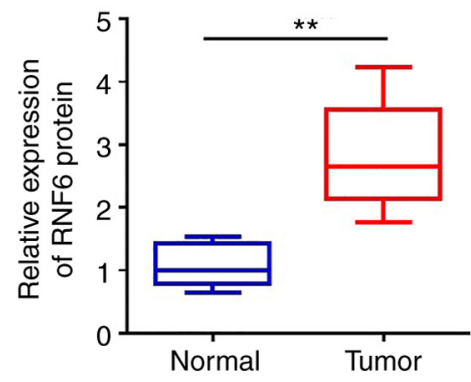

B

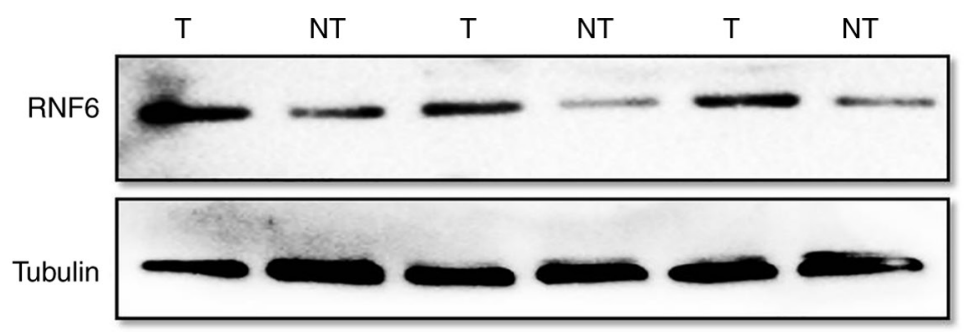

$\mathrm{D}$
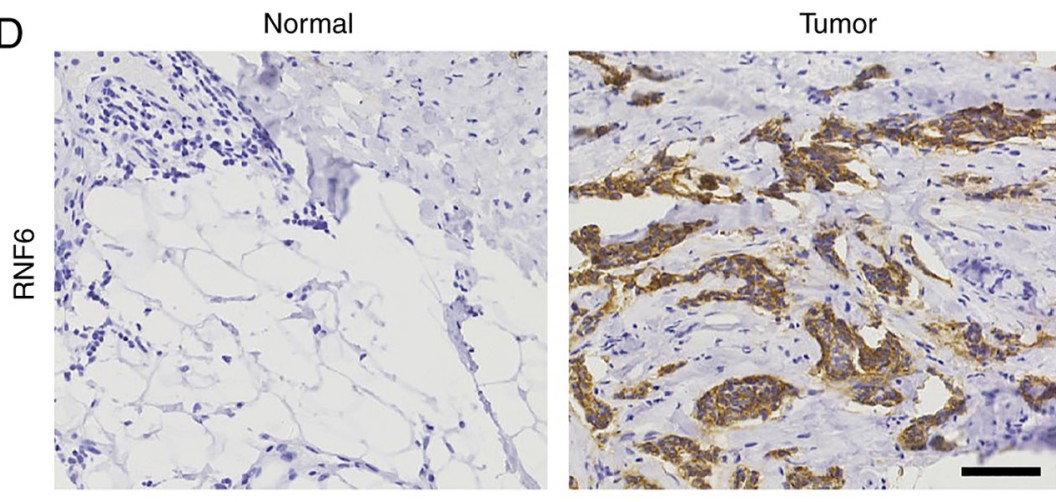

$\mathrm{F}$

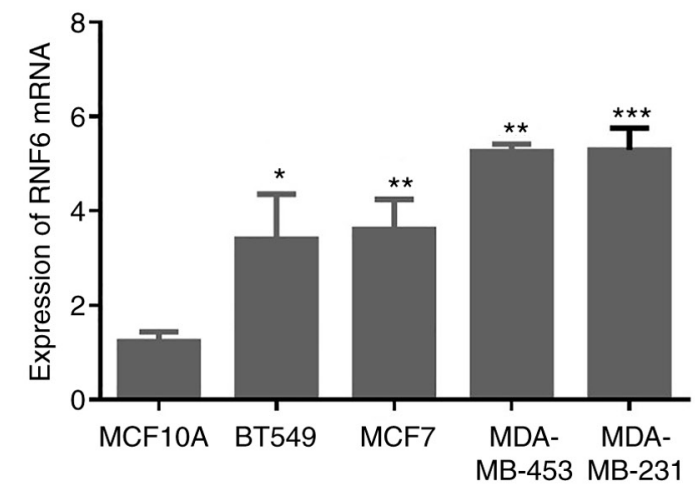

Figure 1. Expression of RNF6 is significantly upregulated in BC tissue. (A) RT-qPCR analysis of RNF6 mRNA expression in 146 BC tumor and paired non-tumor tissue samples. ${ }^{* *} \mathrm{P}<0.01$. (B) Western blotting and (C) quantification of RNF6 protein levels in BC and paired non-tumor tissue. Tubulin was used as a loading control. (D) Representative images of RNF6 staining. Magnification, x400, Scale bar, $100 \mu \mathrm{m}$. (E) Western blotting and (F) RT-qPCR were performed to detect RNF6 protein and mRNA levels in four BC cell lines and MCF10A cells. ${ }^{*} \mathrm{P}<0.05,{ }^{* *} \mathrm{P}<0.01$ and ${ }^{* * *} \mathrm{P}<0.001$ vs. MCF10A. RNF6, ring finger protein 6; BC, breast cancer; RT-q, reverse transcription-quantitative.

the expression of RNF6 in 146 BC and non-tumour adjacent tissue samples obtained from patients with $\mathrm{BC}$. was detected using RT-qPCR. The RT-qPCR data revealed that RNF6 was highly expressed in primary breast cancer tissues compared with adjacent control tissues (Fig. 1A). Furthermore, the protein levels of 60 fresh BC tumour tissues and their paired non-tumour adjacent tissues were quantitatively analysed. In accordance with increased RNF6 mRNA levels, the levels of RNF6 protein in BC tissues were significantly higher compared with adjacent normal tissues (Fig. $1 \mathrm{~B}$ and $\mathrm{C}$ ). The levels of RNF6 protein in BC paraffin-embedded tissue samples and corresponding normal paraffin tissues was detected by IHC with an RNF6 antibody. RNF6 protein was highly expressed in $65.75 \%$ (96 of 146) of the BC tissue samples (Fig. 1D). To investigate the expression of RNF6 in BC cells, the expression levels of RNF6 in BC cell lines and normal human mammary gland cells (MCF10A) were detected. RT-qPCR and western blot data showed that RNF6 expression in BC cells was higher compared with MCF10A cells (Fig. 1E and F). These results demonstrated that high RNF6 levels were observed in BC tissues.

To explore the correlation between RNF6 overexpression and $\mathrm{BC}$ clinicopathological parameters, the expression of RNF6 in BC specimens and clinicopathological characteristics were detected by IHC. RNF6 overexpression was remarkably correlated with tumour stage and lymph node metastasis stages (Table I). In addition, to investigate the efficiency of RNF6 in the survival of patients with BC, the association between RNF6 levels and the survival of patients with BC was investigated. Patients with high RNF6 levels were correlated with poor overall survival and poor disease-free survival compared with patients with low levels of RNF6 (Fig. 2A and B). The results of multivariate Cox regression analysis indicated that high RNF6 levels were an independent predictor of poor survival in patients with $\mathrm{BC}$ (Table II). In summary, these data suggested that RNF6 was upregulated in $\mathrm{BC}$ tissues and associated with unfavorable prognosis in patients with $\mathrm{BC}$. 
Table I. Association between RNF6 expression and clinicopathological features in 146 patients with breast cancer.

\begin{tabular}{|c|c|c|c|c|}
\hline \multirow[b]{2}{*}{ Parameters } & \multirow[b]{2}{*}{$\begin{array}{c}\text { Total cases } \\
146\end{array}$} & \multicolumn{2}{|c|}{ RNF6 expression } & \multirow[b]{2}{*}{ P-value } \\
\hline & & $\begin{array}{l}\text { High } \\
(\mathrm{n}=96)\end{array}$ & $\begin{array}{c}\text { Low } \\
(\mathrm{n}=50)\end{array}$ & \\
\hline Age (years) & & & & $\mathrm{P}=0.302$ \\
\hline$<50$ & 79 & 49 & 30 & \\
\hline$\geq 50$ & 67 & 47 & 20 & \\
\hline Pathological grade & & & & $\mathrm{P}=0.906$ \\
\hline$<2$ & 116 & 76 & 40 & \\
\hline$\geq 2$ & 30 & 20 & 10 & \\
\hline Clinical stage & & & & $\mathrm{P}=0.234$ \\
\hline $\mathrm{I}-\mathrm{II}$ & 97 & 67 & 30 & \\
\hline III-IV & 49 & 29 & 20 & \\
\hline Tumor stage & & & & $P<0.001$ \\
\hline $\mathrm{T} 1-\mathrm{T} 2$ & 86 & 46 & 40 & \\
\hline T3-T4 & 60 & 50 & 10 & \\
\hline Lymph node metastasis stage & & & & $\mathrm{P}=0.004$ \\
\hline N0-N1 & 97 & 56 & 41 & \\
\hline $\mathrm{N} 2$ & 49 & 40 & 9 & \\
\hline Metastasis stage & & & & $\mathrm{P}=0.067$ \\
\hline M0 & 135 & 86 & 49 & \\
\hline M1 & 11 & 10 & 1 & \\
\hline
\end{tabular}

RNF6, ring finger protein 6.
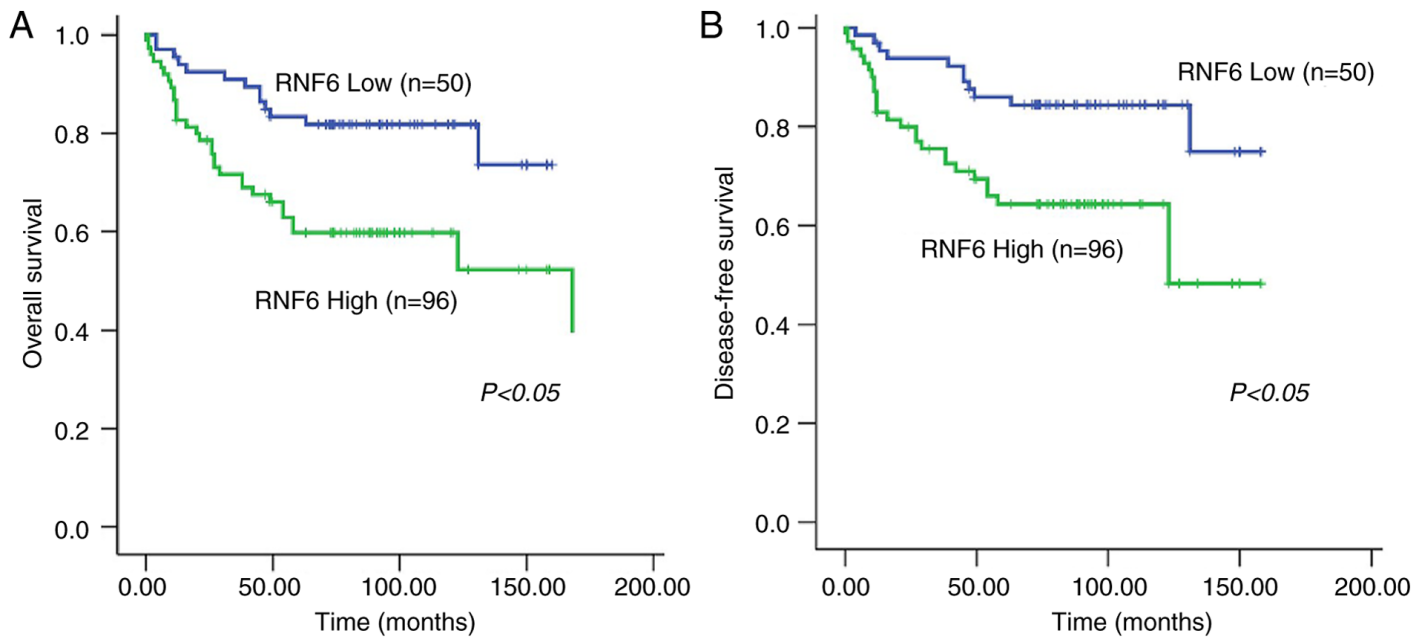

Figure 2. Relative RNF6 expression in BC and its clinical significance. (A) Kaplan-Meier curves for overall survival of two groups defined by low and high expression of RNF6 in patients with BC. (B) Kaplan-Meier curves for disease-free survival of two groups defined by low and high expression of RNF6 in patients with BC. RNF6, ring finger protein 6; BC, breast cancer.

RNF6 promotes the migration and invasion of $B C$ in vivo and in vitro. Since high RNF6 expression correlated with clinical and lymph node metastasis stages, the role of RNF6 in the migration and invasion of BC was investigated. RNF6 shRNA and corresponding controls were used to silence RNF6 expression in MDA-MB-231 and MDA-MB-453 cells with high endogenous RNF6 expression (Fig. 3A and B). A significant decrease in BC cell migration was observed in the shRNF6 group compared with the shNC group (Fig. $3 \mathrm{C}$ and D). Furthermore, stable RNF6 knockdown in BC cells showed lower invasion rates compared with control cells (Fig. 3E). Subsequently, the effect of RNF6 on BC metastasis was investigated using an in vivo tumour metastasis assay. The present results showed fewer lung metastatic nodules in the shRNF6 
Table II. Univariate and multivariate analyses of overall survival in patients with breast cancer.

\begin{tabular}{|c|c|c|c|c|c|c|}
\hline \multirow[b]{2}{*}{ Parameters } & \multicolumn{3}{|c|}{ Univariate analysis } & \multicolumn{3}{|c|}{ Multivariate analysis } \\
\hline & HR & $95 \% \mathrm{CI}$ & P-value & HR & $95 \% \mathrm{CI}$ & P-value \\
\hline Age $(\geq 50 /<50)$ & 0.652 & $0.344-1.431$ & 0.516 & - & - & - \\
\hline Pathological grade $(<2 / \geq 2)$ & 0.812 & $0.516-1.664$ & 0.874 & - & - & - \\
\hline Clinical stage (I-II/III-IV) & 1.814 & $1.121-4.551$ & 0.163 & - & - & - \\
\hline Tumor stage (T1-T2/T3-T4) & 1.757 & $1.163-3.146$ & 0.012 & 1.642 & $0.925-3.426$ & 0.074 \\
\hline $\begin{array}{l}\text { Lymph node metastasis } \\
\text { stage (N0-N1/N2) }\end{array}$ & 1.612 & $1.211-3.441$ & 0.014 & 1.433 & $1.123-2.451$ & 0.021 \\
\hline Metastasis stage (M0/M1) & 0.762 & $0.431-4.134$ & 0.521 & - & - & - \\
\hline RNF6 expression (high/low) & 1.724 & $1.341-3.312$ & 0.006 & 1.532 & $1.121-3.642$ & 0.026 \\
\hline
\end{tabular}

HR, hazard ratio; CI, confidence interval; RNF6, ring finger protein 6.

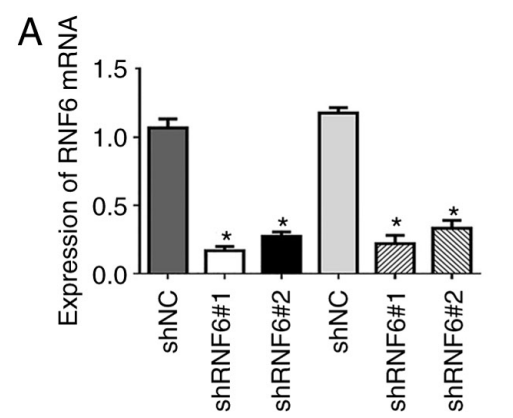

C

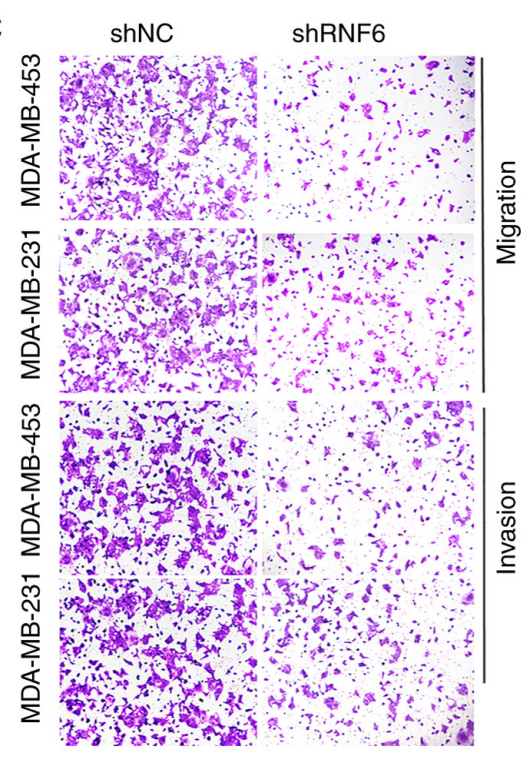

B

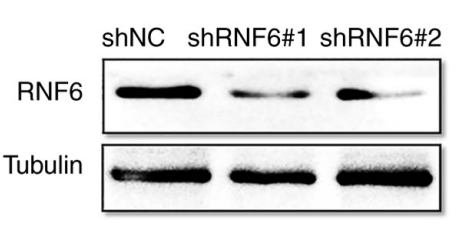

D

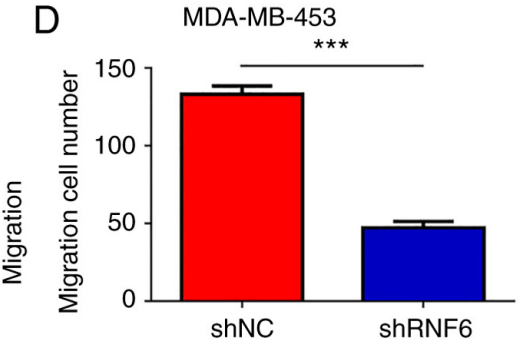

$E$

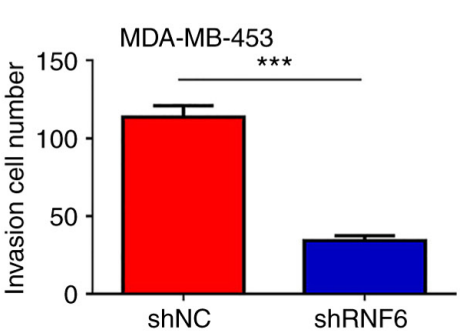

MDA-MB-231

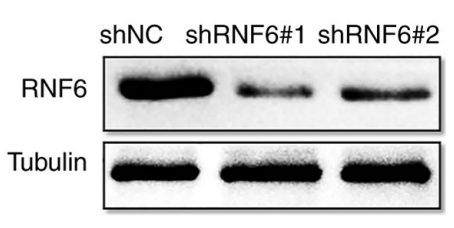

MDA-MB-231

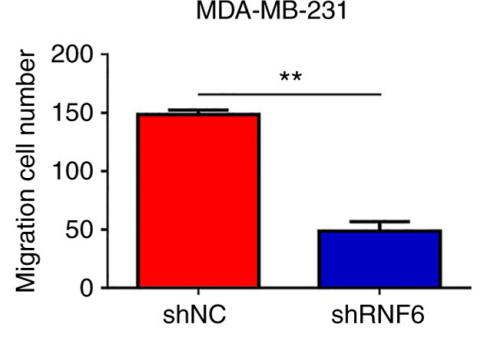

MDA-MB-231

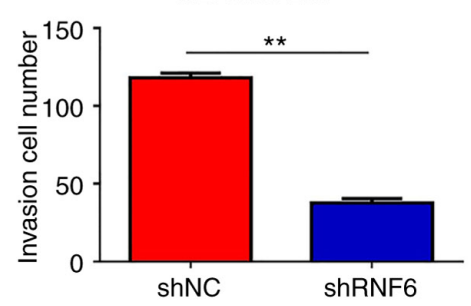

Figure 3. RNF6 knockdown inhibits breast cancer metastasis and invasion in vitro and in vivo. (A) Reverse transcription-quantitative PCR and (B) western blotting were performed to detect RNF6 mRNA and protein expression in MDA-MB-453 and MDA-MB-231 cells stably transfected with shNC or shRNF6. ${ }^{*} \mathrm{P}<0.05$ vs. shNC. (C) Microscopy images of Transwell (D) migration and (E) invasion assays of MDA-MB-453 and MDA-MB-231 cells with stable RNF6 knockdown, Scale bar, $50 \mu \mathrm{m}{ }^{* *} \mathrm{P}<0.01$; ${ }^{* * * *} \mathrm{P}<0.001$. Magnification, $\mathrm{x} 100$. RNF6, ring finger protein 6 ; sh, short hairpin; NC, negative control.

group compared with the control group (Fig. S1). In conclusion, these data indicated that RNF6 promoted the migration and invasion of $\mathrm{BC}$ in vivo and in vitro.

RNF6 facilitates the invasion and migration of BC cells by $Y A P$. To study the mechanism by which RNF6 regulates the invasion and migration of $\mathrm{BC}$ cells, a luciferase reporter assay was performed to screen the signalling pathway downstream of RNF6. As shown in Fig. 4A and B, RNF6 knockdown inhibited YAP activity at the basal level during YAP stimulation. Knockdown of RNF6 expression suppressed the expression of Cyr61, connective tissue growth factor and cyclin E, which are target genes of YAP (Fig. 4C). RNF6 downregulation reduced YAP protein levels compared with controls (Fig. 4D). These 
A
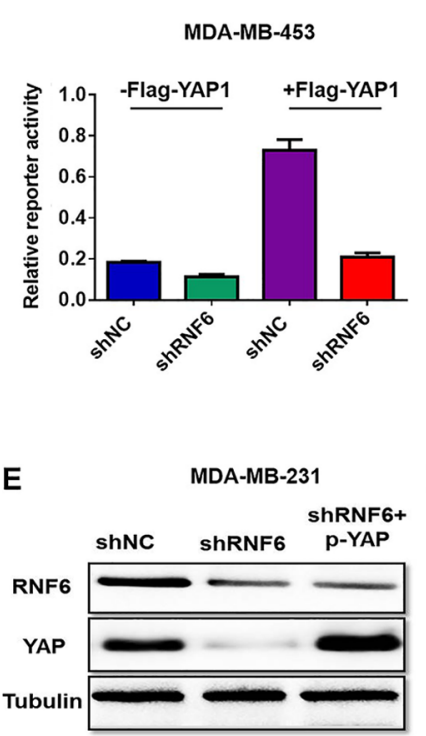

B

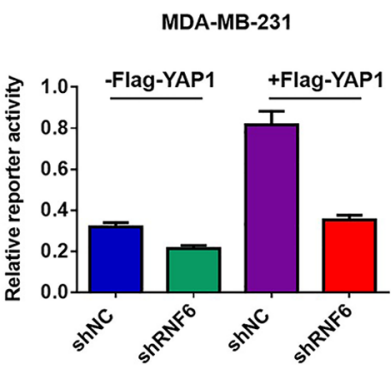

C

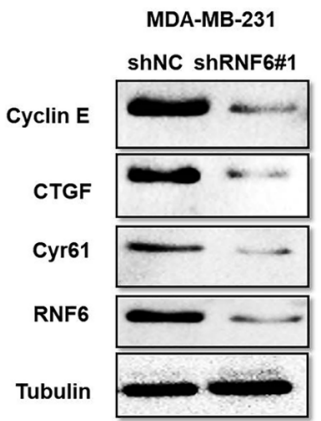

D

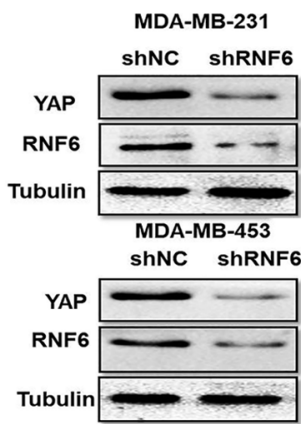

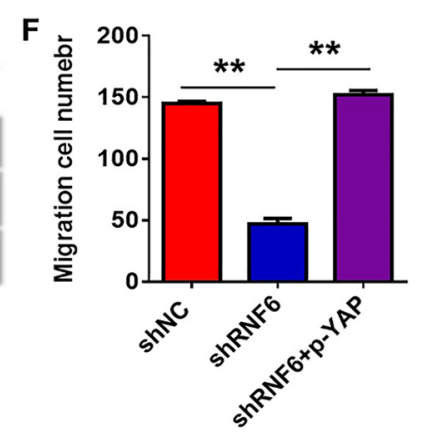

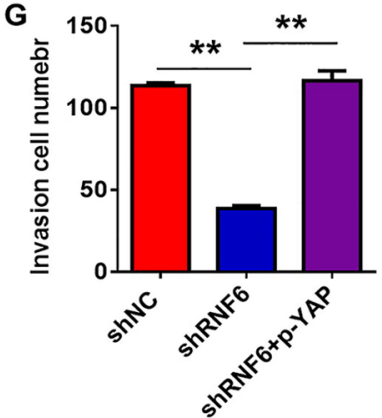

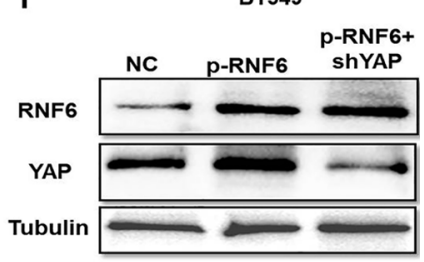
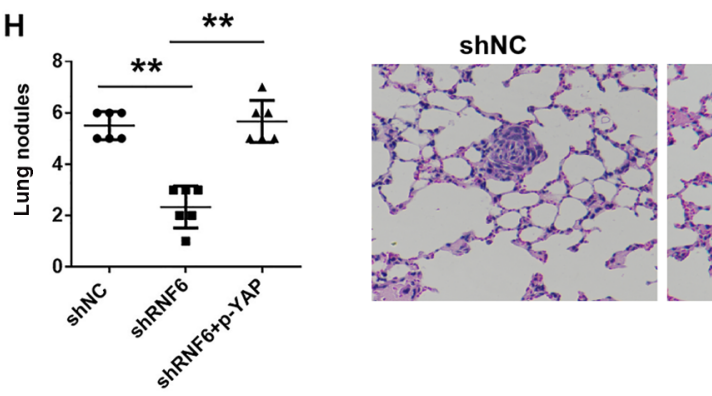

ShRNF6

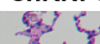

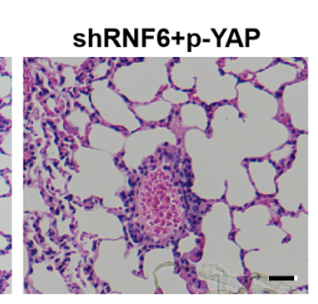
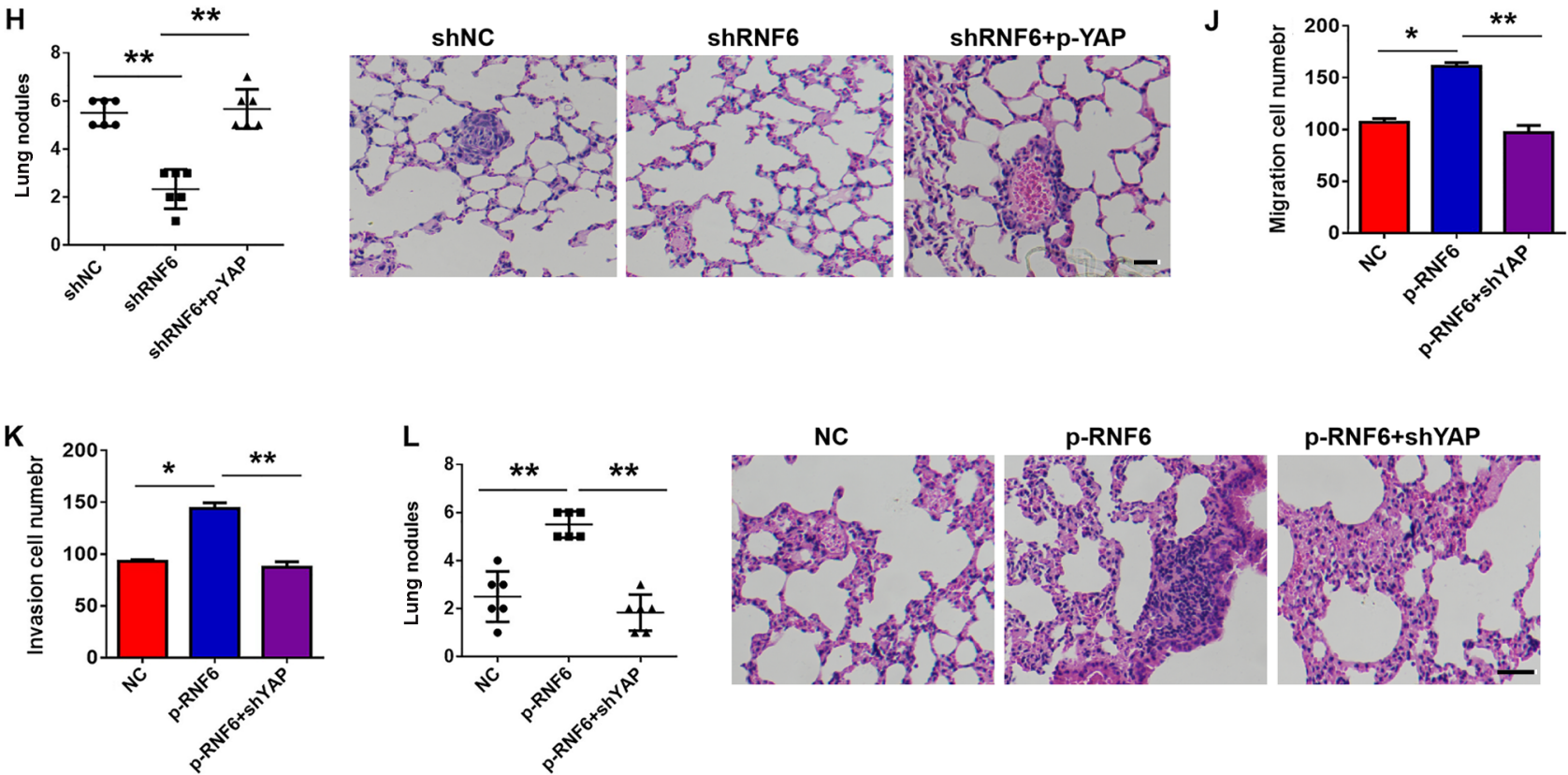

Figure 4. RNF6 promotes migration of breast cancer cells via YAP in vitro and in vivo. Activity of both endogenous and overexpressed YAP was measured using a YAP reporter assay following RNAi-induced RNF6 knockdown in (A) MDA-MB-453 and (B) MDA-MD-231 cells. (C) Levels of Cyr61, CTGF and cyclin E, three target genes of YAP, were assessed by western blotting in MDA-MB-231 cells stably transfected with shNC or shRNF6. (D) Expression levels of YAP were assessed by western blotting in BC cells stably transfected with shNC vector or shRNF6. (E) Western blotting was performed to detect the expression of RNF6 and YAP. Transwell assay showed that upregulation of YAP significantly rescued (F) cell migration and (G) invasion in shRNF6-transfected MDA-MB-231 cells. (H) Statistical analysis of lung metastatic nodules in RNF6 knockdown cells. Magnification, x400. (I) Protein levels of RNF6 and YAP were detected by western blotting. Transwell assay showed that YAP inhibition decreased RNF6-enhanced (J) cell migration and (K) invasion. (L) Statistical analysis of lung metastatic nodules in RNF6-overexpressing cells. $\mathrm{n}=6$ /group. Scale bar, $50 \mu \mathrm{m}$. "P<0.01; * $\mathrm{P}<0.01$. RNF6, ring finger protein 6; YAP, YES-associated protein; CTGF, connective tissue growth factor; sh, short hairpin; NC, negative control.

results indicated that RNF6 regulated the transcriptional activity of YAP by downregulating YAP protein levels. To further investigate whether RNF6 mediates the metastasis and invasion of BC by regulating YAP, YAP was overexpressed in RNF6 knockdown BC cells. Protein expression levels of RNF6 and YAP were measured by western blotting, and cell migration and invasion were investigated by performing
Transwell assays. The western blotting image in Fig. 4E showed that RNF6 downregulation decreased YAP expression and YAP upregulation attenuated the loss of YAP expression in RNF6 knockdown BC cells. The migration and invasion capabilities of MDA-MB-231 cells were significantly reduced by RNF6 knockdown. However, YAP upregulation attenuated the reduction in migration and invasion ability caused 

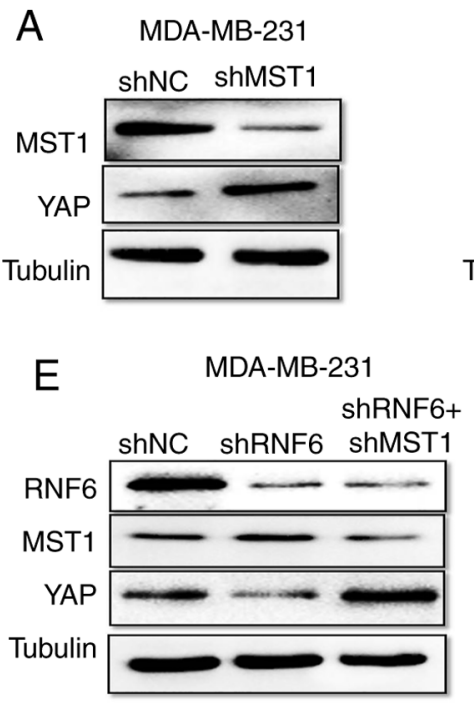
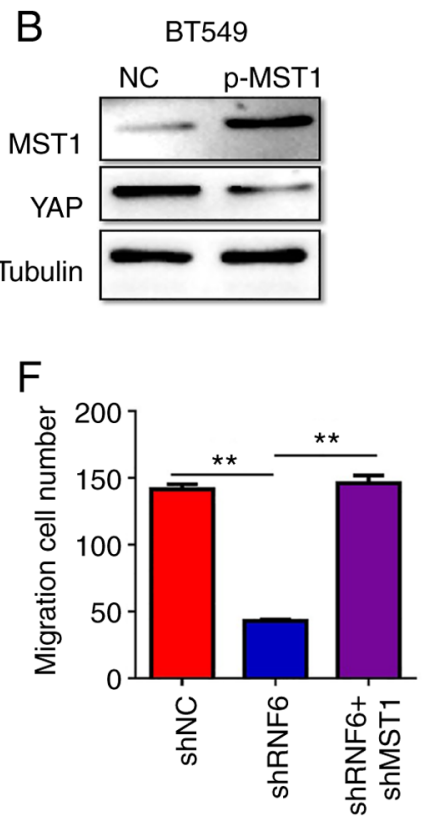

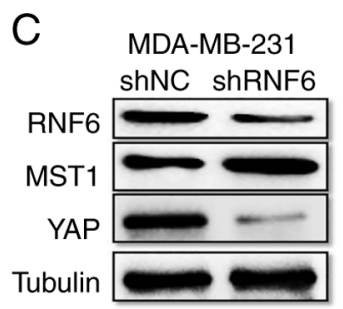

G

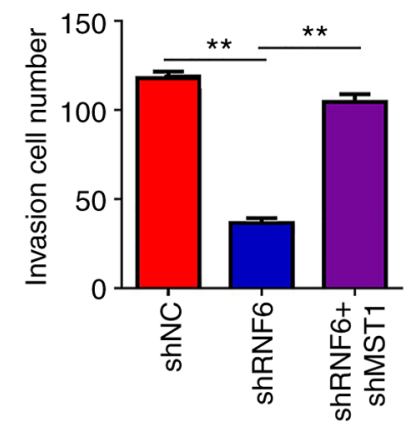

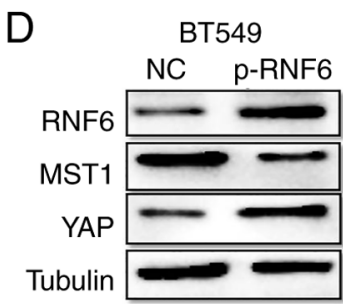

$\mathrm{H}$

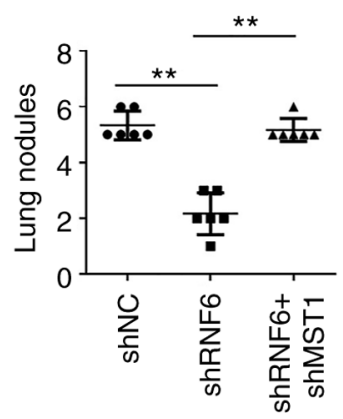

Figure 5. RNF6 regulates YAP-induced BC migration and invasion in an MST1-dependent manner. (A) The expression levels of MST1 and YAP were assessed by Western blotting in BC cells stably transfected with shNC vector or shMST1. (B) The expression levels of MST1 and YAP were assessed by Western blotting in BC cells stably transfected with the vector or p-MST1 plasmid. (C) The expression levels of MST1 and YAP were assessed by Western blotting in BC cells stably transfected with shNC vector or shRNF6. (D) Expression levels of MST1 and YAP were assessed by western blotting in BC cells stably transfected with the vector or p-RNF6 plasmid. (E) Protein levels of RNF6, MST1 and YAP were assessed by western blotting in shRNF6 cells transfected with shMST1. Transwell assay showed the (F) migration and (G) invasion capacity of BC cells stably transfected with shRNF6 in the presence or absence of shMST1. (H) Statistical analysis of lung metastatic nodules. $\mathrm{n}=6$ /group. ${ }^{* *} \mathrm{P}<0.01$. RNF6, ring finger protein 6; YAP, YES-associated protein; BC, breast cancer; MST1, mammalian STE20-like protein kinase 1; shMST1, short hairpin RNA targeting MST1; shNC, short hairpin RNA negative control; p, plasmid.

by RNF6 knockdown (Fig. 4F-H). YAP expression was then knocked down in RNF6-overexpressing cells (Fig. 4I), which reversed the promoting effects of RNF6 on the migration of BC cells (Fig. 4J-L). Collectively, these findings suggested that RNF6-promoted migration and invasion is YAP-dependent in $\mathrm{BC}$ cells.

RNF6 regulates YAP expression via MST1. Numerous studies have shown that MST1 is the main component of YAP signalling $(16,17)$, and regulates the expression of YAP in pancreatic cancer $(18,19)$. Therefore, the present study investigated whether MST1 is involved in RNF6 regulation of YAP in BC. To confirm this hypothesis, the change in YAP expression in shMST1-transfected MDA-MB-231 cells was measured. Compared with their respective NC groups, MST1 knockdown increased YAP expression in MDA-MB-231 cells (Fig. 5A), whereas MST1 upregulation had the opposite effect in BC cells (Fig. 5B). These findings demonstrated that MST1 regulated YAP expression in $\mathrm{BC}$ cells.

To determine whether RNF6 affects YAP expression via MST1, the changes in MST1 and YAP expression in RNF6 knockdown MDA-MB231 cells were further measured. RNF6 knockdown significantly reduced YAP protein expression but increased MST1 protein expression in MDA-MB231 cells compared with the shNC group (Fig. 5C). By contrast, RNF6 overexpression significantly increased YAP protein expression but decreased MST1 protein expression in BC cells compared with the NC group (Fig. 5D). These findings indicated that MST1 is involved in RNF6 regulation of YAP expression. To further verify that RNF6 regulates YAP expression via MST1 in BC cells, MST1 was knocked down in RNF6-deficient BC cells. MST1 downregulation rescued decreased YAP expression in RNF6-deficient MDA-MB231 cells (Fig. 5E), and the cell migration and invasion abilities were also rescued in vitro and in vivo (Fig. 5F-H). These results demonstrated that RNF6 regulated YAP-induced $\mathrm{BC}$ migration and invasion in an MST1-dependent manner.

RNF6 promotes MST1 degradation. To further elucidate the mechanism of RNF6 in regulating MST1 in BC cells, the interaction between RNF6 and MST1 was examined. Immunofluorescence analysis showed that RNF6 and MST1 protein were co-localised in MDA-MB-231 cells (Fig. 6A). In GST pull-down experiments, the results showed that RNF6 is directly combined with MST1 in BC cells (Fig. 6B). Co-IP results further confirmed that there was a direct binding between RNF6 and MST1 (Fig. 6C). In general, these data demonstrated that RNF6 protein interacts with MST1 protein.

Since RNF6 is one of the most important E3 ubiquitin ligases, the present study investigated whether RNF6 induces ubiquitination and degradation of MST1 via the ubiquitin-proteasome system (UPS). As shown in Fig. 6D, significant time-dependent accumulation of MST1 protein was observed in BC cells treated with the proteasome inhibitor MG132. These results demonstrated that MST1 is degraded by the UPS in BC cells. Subsequently, the degradation of MST1 protein in RNF6-deficient cells following exposure to $\mathrm{CHX}$ was tested. The degradation dynamics assay showed that the half-life of the expressed MST1 was significantly decreased in shRNF6-transfected MDA-MB-31 cells compared with 


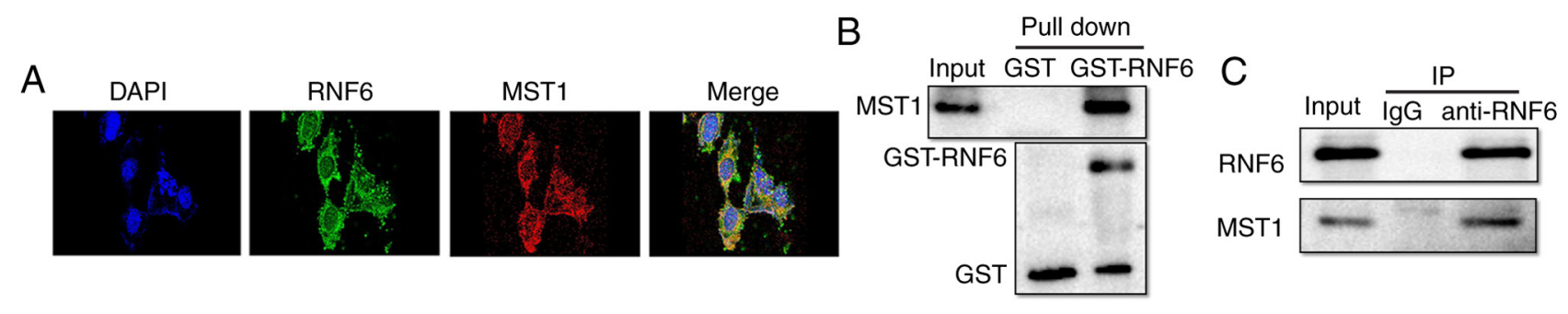

D

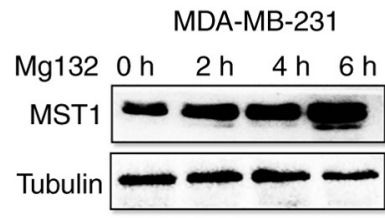

E

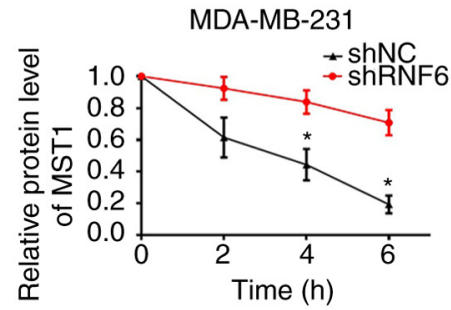

$\mathrm{H}$

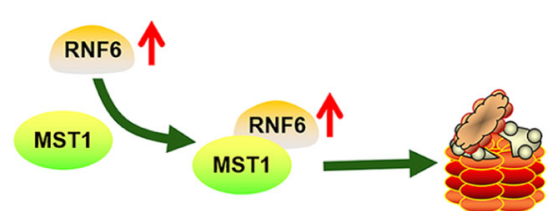

$\mathrm{F}$

MDA-MB-231

G MDA-MB-231

NC shRNF6

NC shRNF6 p-RNF6 NC shRNF6 p-RNF6
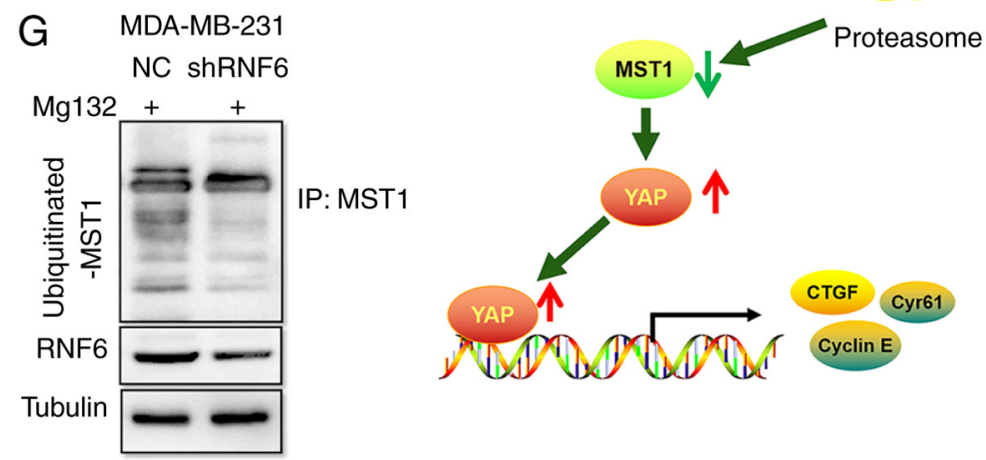

Tubulin

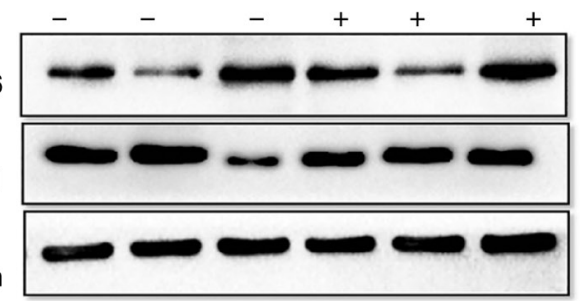

Figure 6. RNF6 accelerates ubiquitination and degradation of MST1 in breast cancer cells. (A) Immunofluorescence staining for MST1 and RNF6 in MDA-MB-231 cells. Magnification, x400. Scale bar, $100 \mu \mathrm{m}$ (B) MDA-MB-231 cell lysates were incubated with GST-RNF6 or GST fusion protein and glutathione-sepharose 4B beads for $3 \mathrm{~h}$ before washing. The elution was subsequently analyzed by western blotting with anti-MST1 antibody. (C) MST1 was blotted on immunoprecipitated endogenous RNF6 in MDA-MB-231 cell lysates. (D) MDA-MB-231 cells were treated with MG132 (15 $\mu$ mol/l) and the protein levels of MST1 were detected. (E) RNF6 knockdown promoted degeneration of MST1 protein in MDA-MB-231 cells. * $\mathrm{P}<0.05$ vs. shRNF6. (F) RNF6 had no effect on MST1 expression, as assessed by western blotting following transfection with shRNF6 or p-RNF6 in BC cells. (G) Cells were treated with proteasomal inhibitor MG132 $(10 \mathrm{mmol} / \mathrm{l})$. Cell lysates were prepared and subjected to immunoprecipitation with anti-MST1 antibody. The levels of Ub-attached MST were detected by western blotting analysis with Ub antibody. $(\mathrm{H})$ Proposed model by which RNF6 promotes migration and invasion of breast cancer by promoting ubiquitination and degradation of MST1. YAP, YES-associated protein; RNF6, ring finger protein 6; MST1, mammalian STE20-like protein kinase 1; sh, short hairpin; Ub, ubiquitin; GST, glutathione S-transferase; NC, negative control; p, plasmid.

shNC-transfected cells (Fig. 6E). The present results showed that RNF6 silencing inhibited MST1 protein degradation in BC cells. Moreover, MST1 protein levels remained unaltered after dysregulation of RNF6 in BC cells following treatment with MG132 (Fig. 6F). Furthermore, RNF6 knockdown significantly reduced the ubiquitination levels of MST1 compared with the NC group (Fig. 6G). Collectively, these findings suggested that RNF6 accelerated the ubiquitination and degradation of MST1 in BC cells.

\section{Discussion}

RNF6, a member of the E3 ligase ring finger family, has been shown to play an important role in the progression of malignant tumours $(7,20)$. However, to the best of our knowledge, the molecular mechanism of RNF6 in BC remains to be elucidated. The present study showed that RNF6 expression levels in the tumours of patients with BC significantly increased compared with normal breast tissue. The present results showed that RNF6 overexpression was remarkably correlated with the clinical, tumour and lymph node metastasis stages of BC. Furthermore, patients with high RNF6 levels were correlated with poor overall survival and disease-free survival compared with patients with low RNF6 levels. The results of multivariate Cox regression analysis indicated that high RNF6 levels were an independent predictor of poor survival in patients with BC. In summary, these data suggested that RNF6 acts as an oncogene in BC tissues and associated with unfavorable prognosis in patients with BC.

Metastasis is a crucial biological feature in cancer and is closely associated with cancer progression (21-23). The high invasiveness and distant metastasis of $\mathrm{BC}$ are considered as the main obstacles of patients with $\mathrm{BC}$ to obtain satisfactory prognosis (21-23). Therefore, it is of significance to understand the mechanism behind $\mathrm{BC}$ metastasis. The present study showed a significant decrease in BC cell migration in the shRNF6 group. Stable RNF6 knockdown in BC cells resulted in lower migration compared with control cells. Furthermore, the present results showed that RNF6 downregulation reduced the expression of YAP, and YAP upregulation reduced the loss of YAP expression in RNF6-deficient BC cells. The present findings demonstrated that RNF6 knockdown significantly reduced the 
migration and invasion ability of cancer cells, and YAP upregulation rescued the decreased migration and invasion ability induced by RNF6 knockdown. These results demonstrated that RNF6 regulates YAP-induced $\mathrm{BC}$ migration and invasion.

Subsequently, the molecular mechanism of RNF6 regulating YAP expression was investigated. Studies have shown that the carcinogenic Hippo-YAP pathway plays a key role in regulating $\mathrm{BC}$ progression, in which MST1 is activated by oxidative stress and plays a central role in the Hippo pathway, controlling cell proliferation, differentiation and apoptosis during development (24-29). The present results showed that MST1 knockdown significantly increased YAP expression in BC cells, whereas MST1 upregulation had the opposite effect in BC cells. These findings suggested that MST1 regulated YAP expression in BC cells. Furthermore, the present data showed that MST1 downregulation rescued decreased YAP expression in RNF6-deficient MDA-MB231 cells, and the cell migration and invasion abilities were also rescued. These results demonstrated that RNF6 regulates YAP-induced BC migration and invasion in an MST1-dependent manner.

Finally, the mechanism by which RNF6 regulated MST1 expression in $\mathrm{BC}$ was further explored. Previous studies have reported that tumor necrosis factor receptor-associated factor 6 regulates YAP signaling by promoting the ubiquitination and degradation of MST1 in pancreatic cancer (30). The present results showed that RNF6 is a novel E3 ubiquitin ligase of MST1, and RNF6 induced ubiquitination and degradation of MST1 through the UPS. This conclusion is mainly based on the following reasons. First, the present results showed that RNF6 protein interacted with MST1 protein. Second, significant accumulation of MST1 protein was observed in BC cells treated with MG132. These results indicated that MST1 is degraded by the UPS in BC cells. Third, the present results showed that RNF6 silencing promoted MST1 protein degradation in BC cells. Moreover, MST1 protein levels remained unchanged after dysregulation of RNF6 in BC cells following treatment with MG132. In addition, RNF6 knockdown significantly reduced the ubiquitination levels of MST1.

In conclusion, the present study provided evidence that RNF6 plays an oncogenic role in BC. We not only clarified the role of RNF6 in breast cancer metastasis, but also provided insights into the mechanism of RNF6 via mediating the MST1/YAP axis (Fig. 6H). These results highlighted the important role of RNF6 expression, which may be used as a prognostic indicator and therapeutic target for future breast cancer treatment.

\section{Acknowledgements}

Not applicable.

\section{Funding}

This study was supported by a grant from the National Natural Science Foundation of China (grant no. 81960503).

\section{Availability of data and materials}

The datasets used and/or analyzed during the current study are available from the corresponding author on reasonable request.

\section{Authors' contributions}

$\mathrm{YH}$ and $\mathrm{YZ}$ performed the in vitro experiments and analyzed the data. YH performed the animal experiments. YZ collected the clinical tissue samples. ZJ and YH designed the study, wrote the manuscript and revised the manuscript. All authors confirm the authenticity of all the raw data. All authors read and approved the final manuscript.

\section{Ethics approval and consent to participate}

The current study was approved by the Ethics Committee of the First Affiliated Hospital of Nanchang University and the Third Hospital of Nanchang, and written informed consent was obtained from the parents or guardians of all patients. The animal studies were approved by the Ethical Committee of the First Affiliated Hospital of Nanchang University and the Third Hospital of Nanchang.

\section{Patient consent for publication}

Not applicable.

\section{Competing interests}

The authors declare that they have no competing interests.

\section{References}

1. Siegel RL, Miller KD and Jemal A: Cancer statistics, 2018. CA Cancer J Clin 68: 7-30, 2018.

2. Chan BK, Wiseberg-Firtell JA, Jois RH, Jensen K and Audisio RA: Localization techniques for guided surgical excision of non-palpable breast lesions. Cochrane Database Syst Rev: CD009206, 2015.

3. Sharma R, Sharma R, Khaket TP, Dutta C, Chakraborty B and Mukherjee TK: Breast cancer metastasis: Putative therapeutic role of vascular cell adhesion molecule-1. Cell Oncol (Dordr) 40: 199-208, 2017.

4. Liu L, Zhang Y, Wong CC, Zhang J, Dong Y, Li X, Kang W, Chan FKL, Sung JJY and Yu J: RNF6 promotes colorectal cancer by activating the $\mathrm{Wnt} / \beta$-catenin pathway via ubiquitination of TLE3. Cancer Res 78: 1958-1971, 2018.

5. Liang Q, Ma D, Zhu X, Wang Z, Sun TT, Shen C, Yan T, Tian X, Yu T, Guo F, et al: RING-finger protein 6 amplification activates JAK/STAT3 pathway by modifying SHP-1 ubiquitylation and associates with poor outcome in colorectal cancer. Clin Cancer Res 24: 1473-1485, 2018.

6. Cai J, Xiong Q, Jiang X, Zhou S and Liu T: RNF6 facilitates metastasis and radioresistance in hepatocellular carcinoma through ubiquitination of FoxA1. Exp Cell Res 374: 152-161, 2019.

7. Xu K, Shimelis H, Linn DE, Jiang R, Yang X, Sun F, Guo Z, Chen $\mathrm{H}, \mathrm{Li} \mathrm{W}$, Chen $\mathrm{H}$, et al: Regulation of androgen receptor transcriptional activity and specificity by RNF6-induced ubiquitination. Cancer Cell 15: 270-282, 2009.

8. Lo HS, Hu N, Gere S, Lu N, Su H, Goldstein AM, Taylor PR and Lee MP: Identification of somatic mutations of the RNF6 gene in human esophageal squamous cell carcinoma. Cancer Res 62: 4191-4193, 2002.

9. Qin X, Chen S, Qiu Z, Zhang Y and Qiu F: Proteomic analysis of ubiquitination-associated proteins in a cisplatin-resistant human lung adenocarcinoma cell line. Int J Mol Med 29: 791-800, 2012.

10. Hippo signaling mediates ferroptosis in malignant mesothelioma. Cancer Discov 9: 1155, 2019.

11. Turunen SP, von Nandelstadh P, Öhman T, Gucciardo E, Seashore-Ludlow B, Martins B, Rantanen V, Li H, Höpfner K, Östling P, et al: FGFR4 phosphorylates MST1 to confer breast cancer cells resistance to MST1/2-dependent apoptosis. Cell Death Differ 26: 2577-2593, 2019. 
12. Gomez M, Kulaberoglu Y and Hergovich A: MST1/2 kinase assays using recombinant proteins. Methods Mol Biol 1893: 319-331, 2019.

13. Ji XY, Zhong G and Zhao B: Molecular mechanisms of the mammalian Hippo signaling pathway. Yi Chuan 39: 546-567, 2017

14. He L, Yuan L, Sun Y, Wang P, Zhang H, Feng X, Wang Z, Zhang W, Yang C, Zeng YA, et al: Glucocorticoid receptor signaling activates TEAD4 to promote breast cancer progression. Cancer Res 79: 4399-4411, 2019.

15. Tang DE, Dai Y, Lin LW, Xu Y, Liu DZ, Hong XP, Jiang HW and Xu SH: STUB1 suppresseses tumorigenesis and chemoresistance through antagonizing YAP1 signaling. Cancer Sci 110: 3145-3156, 2019.

16. Chen M, Zhang H, Shi Z, Li Y, Zhang X, Gao Z, Zhou L, Ma J, Xu Q, Guan J, et al: The MST4-MOB4 complex disrupts the MST1-MOB1 complex in the Hippo-YAP pathway and plays a pro-oncogenic role in pancreatic cancer. J Biol Chem 293: 14455-14469, 2018.

17. Dent P, Booth L, Roberts JL, Liu J, Poklepovic A, Lalani AS, Tuveson D, Martinez J and Hancock JF: Neratinib inhibits Hippo/YAP signaling, reduces mutant K-RAS expression, and kills pancreatic and blood cancer cells. Oncogene 38: 5890-5904, 2019.

18. Lipkowitz S and Weissman AM: RINGs of good and evil: Ring finger ubiquitin ligases at the crossroads of tumour suppression and oncogenesis. Nat Rev Cancer 11: 629-643, 2011.

19. Fang S, Lorick KL, Jensen JP and Weissman AM: Ring finger ubiquitin protein ligases: Implications for tumorigenesis, metastasis and for molecular targets in cancer. Semin Cancer Biol 13: $5-14,2003$

20. Zhu L, Tong G, Chen J, Wang Y, Wang S, Zhao M, Li J and Ma J: Cloning and identification of a novel RNF6 transcriptional splice variant Spg2 in human development. Sci China C Life Sci 51: 302-307, 2008.

21. Viale G, Hanlon Newell AE, Walker E, Harlow G, Bai I, Russo L, Dell'Orto P and Maisonneuve P: Ki-67 (30-9) scoring and differentiation of Luminal A- and Luminal B-like breast cancer subtypes. Breast Cancer Res Treat 178: 451-458, 2019.

22. Chen JY, Lai YS, Chu PY, Chan SH, Wang LH and Hung WC: Cancer-derived VEGF-C increases chemokine production in lymphatic endothelial cells to promote CXCR2-dependent cancer invasion and MDSC recruitment. Cancers (Basel) 11: $1120,2019$.
23. Paoletti C, Miao J, Dolce EM, Darga EP, Repollet MI, Doyle GV, Gralow JR, Hortobagyi GN, Smerage JB, Barlow WE and Hayes DF: Circulating tumor cell clusters in metastatic breast cancer patients: A SWOG S0500 translational medicine study. Clin Cancer Res 25: 0208.2019, 2019.

24. D'Agostino L, Nie Y, Goswami S, Tong K, Yu S, Bandyopadhyay S, Flores J, Zhang X, Balasubramanian I, Joseph I, et al: Recycling endosomes in mature epithelia restrain tumorigenic signaling. Cancer Res 79: 4099-4112, 2019.

25. Salah Z, Melino G and Aqeilan RI: Correction: Negative regulation of the Hippo pathway by E3 ubiquitin ligase ITCH is sufficient to promote tumorigenicity. Cancer Res 79: 3007, 2019.

26. Pan Z, Tian Y, Cao C and Niu G: The emerging role of YAP/TAZ in tumor immunity. Mol Cancer Res 17: 1777-1786, 2019.

27. Wu J, Minikes AM, Gao M, Bian H, Li Y, Stockwell BR, Chen $\mathrm{ZN}$ and Jiang $\mathrm{X}$ : Intercellular interaction dictates cancer cell ferroptosis via NF2-YAP signalling. Nature 572: 402-406, 2019.

28. Gobbi G, Donati B, Do Valle IF, Reggiani F, Torricelli F, Remondini D, Castellani G, Ambrosetti DC, Ciarrocchi A and Sancisi V: The Hippo pathway modulates resistance to BET proteins inhibitors in lung cancer cells. Oncogene 38: 6801-6817, 2019.

29. Huang W, Hu H, Zhang Q, Wu X, Wei F, Yang F, Gan L, Wang N, Yang X and Guo AY: Regulatory networks in mechanotransduction reveal key genes in promoting cancer cell stemness and proliferation. Oncogene 38: 6818-6834, 2019.

30. Li JA, Kuang T, Pu N, Fang Y, Han X, Zhang L, Xu X, Wu W, Wang D, Lou W and Rong Y: TRAF6 regulates YAP signaling by promoting the ubiquitination and degradation of MST1 in pancreatic cancer. Clin Exp Med 19: 211-218, 2019.

This work is licensed under a Creative Commons Attribution-NonCommercial-NoDerivatives 4.0 International (CC BY-NC-ND 4.0) License. 